\title{
Resources and reproductive success in women with an example from the Kipsigis of Kenya
}

\author{
Monique Borgerhoff Mulder \\ Evolution and Human Behavior Program, Rackham Building, University of Michigan, \\ Ann Arbor, Michigan 48109, USA.
}

(Accepted 18 May 1987)

(With 2 figures in the text)

Contrary to findings in studies of many mammalian species, the relationship between resources and reproductive success of women is highly variable across societies. This has led some social scientists to suggest that evolutionary biological models are inappropriate to the study of human social behaviour. This paper proposes that variability in the relationship between resources and reproductive success arises from an inadequate specification of the nature and availability of resources critical to reproduction and a failure to understand the mechanisms whereby resources confer reproductive differentials in different environments. Data are presented from the Kipsigis of Kenya showing how land ownership affects female reproductive success; reasons why the effects of landholding are changing over time are examined.

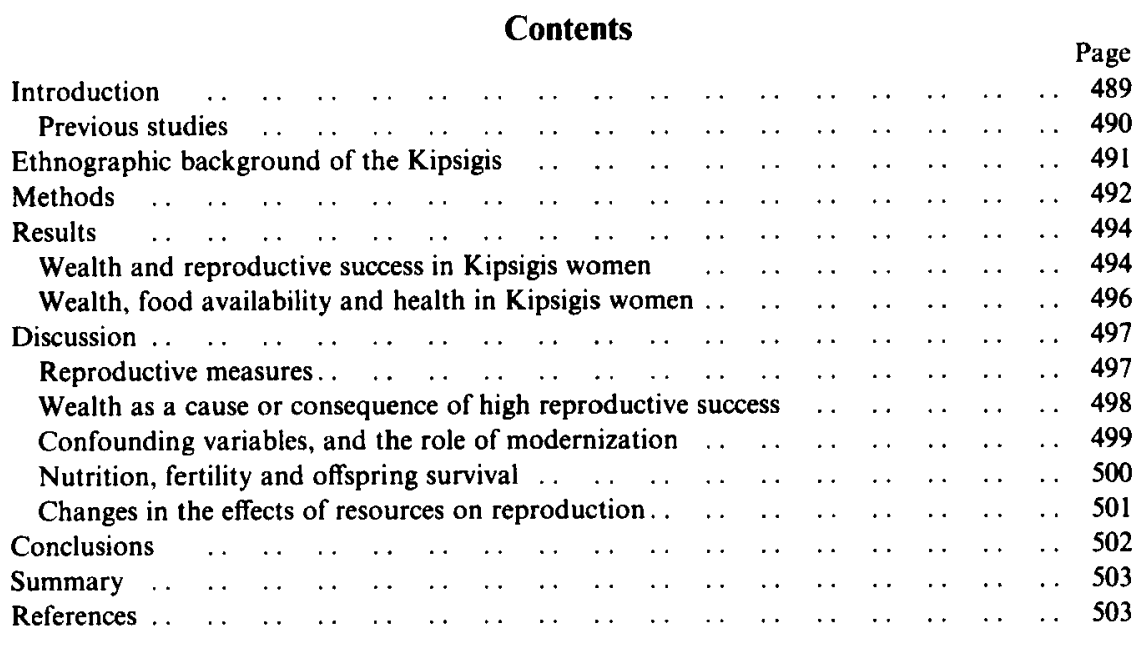

\section{Introduction}

Differential access to resources is emerging as a key determinant of fitness in female mammals (Clutton-Brock, Guinness \& Albon, 1982; Whitten, 1983) and has become a principal tenet of many theories that attempt to relate ecology to social organization (e.g. Wrangham, 1979; 
Vehrencamp \& Bradbury, 1984). In humans the evidence for such an association is inconsistent; indeed there are many cases where wealth and family size are inversely correlated, as in modern western nations (Reed \& Palm, 1951). The lack of a consistent relationship between wealth and completed family size has been taken to indicate that access to resources is not an important determinant of reproductive success and, more radically, that evolutionary biological theory may in some contexts be inappropriate to the study of human social behaviour (Vining, 1986).

This paper suggests that the contradictory results arising from studies of the relationship between resources and reproduction in women across different societies can be traced to two factors: an inadequate specification of the nature and availability of the resources critical to reproduction, and a failure to understand the mechanisms whereby resources confer reproductive success. First, the association between access to resources and female reproductive success in traditional, developing, pre-industrial and modern societies is reviewed. Second, data are presented on the relationship between wealth and reproductive success of women of the Kipsigis of Kenya (for men, see Borgerhoff Mulder, in press $a$ ), focusing on the components of reproductive success that are affected by wealth, possible reasons why reproductive differentials exist between rich and poor women, and changes in the association between wealth and reproductive success that have occurred during the last 50 years of social and economic change. Third, on the basis of the Kipsigis findings, suggestions are made as to why the relationship between differential access to resources and reproductive success is not found consistently in all societies. The conclusion reached is that variability in the relationship between resources and reproductive success does not imply that evolutionary biological models are inappropriate to the study of humans.

\section{Previous studies}

Studies of the relationship between resources and reproductive success of women have produced mixed results. Generally, in rural areas, where access to resources is measured in terms of land ownership, the associations are positive (e.g. Chinese peasants of the 1930s: Lang, 1946; Polish peasantry after World War II: Stys, 1957; Indian villagers: Driver, 1963; farmers in Punjab, Philippines and 15th century Tuscany: reviewed in Simon, 1974; Iranian villagers: Ajami, 1976; Brazilian and North American pioneers: Merrick, 1978; Javanese and Nepalese peasants: Nag, White \& Peet, 1978; Bangladesh farmers: Shaikh \& Becker, 1985). In other studies, particularly where access to resources is measured in terms of the husband's occupation, income or capital assets, the relationship between resources and women's reproductive success is less consistent. From the enormous literature on the demographic effects of socioeconomic status measured in this way, studies can be picked showing relationships that are positive and statistically significant (e.g. Ifalukese horticulturalists of Micronesia: Turke \& Betzig, 1985), positive but non-significant (Yomut pastoralists of Iran: Irons, 1979; Trinadadian villagers: Flinn, 1986; and some preindustrial European populations: Shorter, 1975), or negative (Lebanese: Yaukey, 1961; Iranian villagers: Good, Farr \& Good, 1980; Malian Tamasheq pastoralists: Hill \& Randall, 1984). Finally, in modern industrial and developed nations, inverse relationships between wealth and family size are commonly observed (reviewed by Reed \& Palm, 1951; Wrong, 1961; Vining, 1986), although there are exceptions (see Wrigley, 1966; Hawthorn, 1970; Simon, 1974; Essock-Vitale, 1984).

This brief review demonstrates the variability in the relationship between measures of wealth and female fitness, and raises at least three questions: to what extent are these studies methodologically sound? By what mechanisms can wealth affect female reproductive success? And 
to what can the cross-cultural variability in the association between wealth and female reproductive success be attributed?

In the next two sections some of these methodological and conceptual issues will be explored, using data on the association between wealth and reproductive success in the Kipsigis.

\section{Ethnographic background to the Kipsigis}

The Kipsigis are Nilo-Hamitic people living in the Kericho District of south-western Kenya. Until the 1930s they were largely pastoralists, raising large herds of cattle and goats over communally owned areas (Peristiany, 1939). After 1930 maize was introduced as a subsistence (and subsequently cash) crop, a development that led to the emergence of individual land holdings (Manners, 1967). Kipsigis live in scattered homesteads consisting of the separate households of a number of patrilineally related kin with their wives and children. Mąrriage requires a payment of livestock and cash to the prospective bride's father (bridewealth), is highly stable and, at least among wealthier men, is usually polygynous (Borgerhoff Mulder, in press $a, c$ ).

Cattle and land are owned and inherited by men, and it is only through marriage that women acquire rights to these critical sources of subsistence. In polygynous families, rights to a man's property are split equally between his wives (Peristiany, 1939; Manners, 1967). Each wife has her own house and barn, she cultivates her share of the maize plot, and milks those cows in the herd that have been allocated to her exclusive use. Any cash raised through the sale of a woman's maize or cattle should be given to, or used for, her and her children. Women therefore can be considered as managing a largely economically independent household.

With access to land and cattle a woman can independently earn cash through the sale of foodstuffs, most importantly milk, meat, maize, eggs and vegetables. These products are generally only sold when in excess of the family's needs. An additional form of cash enterprise adopted by women is the illegal sale of a thick maize/millet beer. However, home brewing is extremely labourintensive, constitutes a major drain on the family's crucial supply of stored maize and is viewed as a somewhat desperate measure for raising cash.

The most important nutritional subsistence items are milk, meat, maize, vegetables and eggs. Cash raised through the sale of cattle, maize, surplus food items and beer is used to buy sugar, tea, salt, oil, utensils, blankets, medical care, clothes, school pads, veterinary preparations and other miscellaneous goods.

Women undergo clitoridectomy on reaching menarche (Orchardson, 1961), after which they spend a period which used to be two years, but is now two to three months, in seclusion huts. They are married almost immediately after leaving this seclusion, and have little or no choice in selection of spouse. Women continue to perform agricultural, domestic and husbandry work throughout pregnancy and give birth in their own huts, usually assisted by older women (Peristiany, 1939). Infants are breast-fed for two to three years, although cow's milk and millet/maize porridge may be introduced after three months. The typical interval between births is three years. There are no traditional contraceptive techniques; modern methods were not used by any women in the sample.

The principal cause of mortality of offspring, primarily of children up to five years of age, is disease (discussed in Borgerhoff Mulder \& Milton, 1985) - notably malaria, measles, diarrhoea and influenza. Traditional herbal remedies are available for these maladies, and western medicine has become increasingly accessible in recent years; for example, two hospitals were established at $45 \mathrm{~km}$ from the study site in the 1950s, government dispensaries at 2 and $8 \mathrm{~km}$ in the $1960 \mathrm{~s}$ and a 
TABLE I

Pearson correlation coefficients between acres-perwife and reproductive success in five cohorls of Kipsigis women $^{\mathrm{a} . \mathrm{b}}$

\begin{tabular}{lccc}
\hline $\begin{array}{c}\text { Cohort } \\
\text { (date of marriage) }\end{array}$ & Pearson's $r$ & $N$ & $P$-value \\
\hline $\begin{array}{c}\text { Maina' } \\
(1930-1939)\end{array}$ & 0.13 & 55 & N.S. \\
$\begin{array}{c}\text { Chuma' } \\
(1940-1953)\end{array}$ & 0.23 & 201 & $<0.001$ \\
$\begin{array}{c}\text { Cohort I } \\
(1954-1963)\end{array}$ & 0.22 & 184 & $<0.01$ \\
$\begin{array}{c}\text { Cohort II } \\
(1964-1973)\end{array}$ & 0.08 & 258 & N.S. \\
$\begin{array}{c}\text { Cohort III } \\
(1974-1978)\end{array}$ & 0.21 & 183 & $<0.01$ \\
\hline
\end{tabular}

'For women of the 'Maina' and 'Chuma' cohorts, number of surviving offspring was used as the measure of reproductive success and is equivalent to lifetime reproductive success. For the women of the subsequent cohorts, reproductive success is measured as the number of surviving offspring per year, thus controlling for differential truncation of marital careers even within cohorts.

b Raw correlation coefficients are given. The associations between acres-per-wife and reproductive success were independent of all other measured significant factors affecting reproductive success in each cohort-husband's age, widowed status and age at menarche in Cohort I $\left(f_{1,77}=2.97,0.05<P<0.10\right)$ and wife's education in Cohort III $\left(f_{1,177}=6.45\right.$, $P<0.001$ : see Borgerhoff Mulder, in press $c$ ).

c Women married after 1978 were excluded, see Methods.

Catholic missionary dispensary within the study area in 1983. No preventative or prophylactic medicines are used with the exception of infant immunization which is now becoming widespread.

\section{Methods}

The study site of approximately $35 \mathrm{~km}^{2}$ lies on the border of Kericho and Narok Districts, incorporating Kipsigis living in both Districts (Borgerhoff Mulder, 1985). Between June 1982 and December 1983 all married women and unmarried mothers were interviewed in their language to determine date of birth, clitoridectomy, marriage, the number of surviving offspring and (where possible) the number of live births (for details on demographic methods see Borgerhoff Mulder, in press $a, c$ ). Past life history events could be accurately dated to the year by cross-referencing with male circumcision ceremonies, severe droughts and other incidents of known date.

Women's reproductive success was broken down into three components: length of married reproductive lifespan, calculated as the date of last live-birth minus date of marriage; fertility, calculated as the number of live-births divided by length of married reproductive lifespan; and offspring survival, calculated as the number of offspring surviving to 21 years (or to the present if born after 1963) divided by the number of live- 


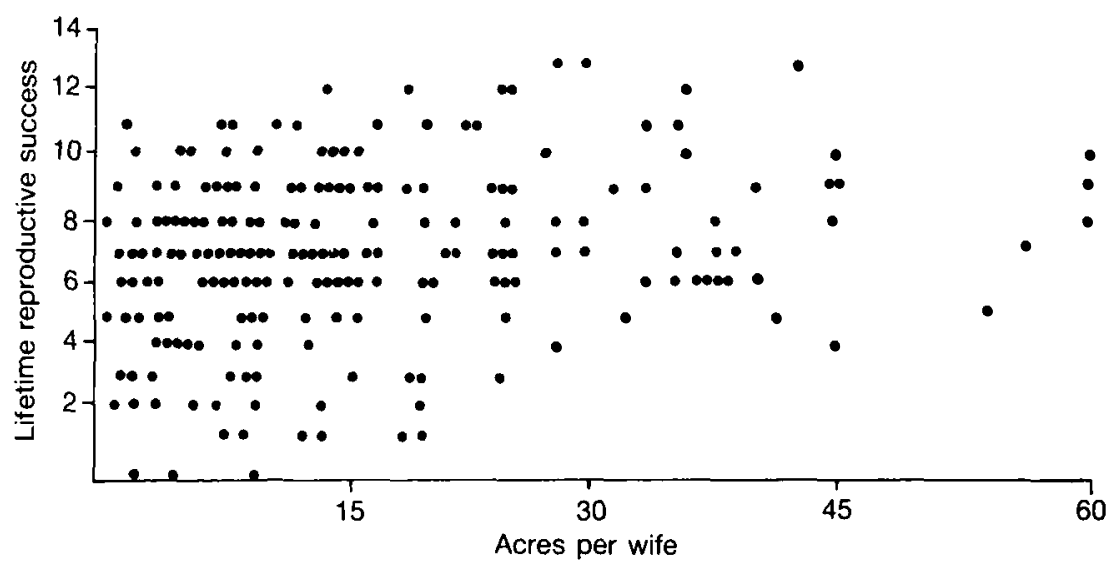

FIG. 1. Lifetime reproductive success for 201 women of the 'Chuma' cohort (married 1940-1953), plotted against acresper-wife $(r=0.23, N=201, P<0.001)$.

TABle II

Pearson correlation coefficients between acres-per-wife, offspring survital and fertility in five cohorts of Kipsigis women

\begin{tabular}{lccccc}
\hline \multicolumn{1}{c}{$\begin{array}{c}\text { Offspring survival" } \\
\text { Cohort }\end{array}$} & \multicolumn{2}{c}{ Fertility } & \\
(date of marriage) & Pearson's $r$ & $P$-value & Pearsons's $r$ & $P$-value & $N$ \\
\hline $\begin{array}{l}\text { Maina' } \\
(1930-1939)\end{array}$ & 0.12 & N.S & -0.02 & N.S. & 40 \\
$\begin{array}{l}\text { 'Chuma' } \\
(1940-1953)\end{array}$ & 0.22 & $<0.01$ & 0.09 & N.S. & 174 \\
$\begin{array}{l}\text { Cohort I } \\
(1954-1963)\end{array}$ & 0.18 & $<0.01$ & 0.22 & $<0.01$ & 166 \\
$\begin{array}{l}\text { Cohort II } \\
(1964-1973)\end{array}$ & 0.00 & N.S. & 0.08 & N.S. & 245 \\
$\begin{array}{l}\text { Cohort III } \\
(1974-1978)\end{array}$ & 0.11 & N.S. & 0.16 & $<0.05$ & 176 \\
\hline
\end{tabular}

"The effects of acres-per-wife on offspring survival were independent of other significant measured factors affecting offspring survival in each cohort-husband's age in the 'Chuma' cohort $\left(f_{1.171}=12.00, P<0.001\right)$ and education in Cohort $I\left(f_{1.163}=2 \cdot 77,0.05<P<0 \cdot 10\right)$.

'The effects of acres-per-wife on fertility were independent of other significant measured factors affecting fertility in each cohort-husband's age, age at menarche and marriage year in Cohort I $\left(f_{1,70}=3.44, P<0.05\right)$ and widowed status in Cohort III $\left(f_{1.173}=4.95, P<0.05\right)$. 
births. Where the ages of deceased offspring were known, the probabilities of surviving infancy $(<18$ months), early childhood ( 18 months to 5 years) and adolescence were calculated.

Women were divided into five cohorts according to the year of their marriage. Two cohorts of women, 'Maina' (married 1930-1939) and 'Chuma' (1940-1953) had entirely terminated their reproductive careers by 1983 so lifetime reproductive success could be measured. The three subsequent cohorts, Cohort I (19541963), Cohort II (1964-1973) and Cohort III (1974-1983) were still reproductive, and a more appropriate measure of reproductive performance was the number of surviving offspring produced per year, calculated as the number of surviving offspring divided by the length of the married reproductive career to date.

Women were excluded from the sample if they had permanently run away from their husbands $(N=46)$, were unmarried $(N=28)$ or were institutionally 'married' to another woman (see Peristiany, 1939) $(N=7)$, because their reproductive careers did not reflect the conditions of normal married life and were not amenable to the same types of analysis. Women married after 1978 were also dropped because of extreme values arising from sampling such short segments of a woman's reproductive career $(N=121)$. The maximum sample sizes of suitable women for the five cohorts were respectively $69,211,187,260$ and 189 , although information on wealth and other independent variables was only available for subsets of these women.

The capital assets (including land, livestock, farm equipment and household items such as buckets and blankets) of each man were censused (Borgerhoff Mulder, in press $a$ ). Because these measures were highly intercorrelated, the size of a man's plot of land was used as a standard measure of wealth differences between men, because it was stable over time and could be verified using government records. To determine the availability of resources to women, the number of acres owned by the husband was divided by the number of his wives, living or dead, to produce a measure of acres-per-wife, an appropriate procedure given the equal division of resources among Kipsigis co-wives.

A behavioural study was conducted among a subsample of households $(N=118)$ between November 1982 and December 1983 (see Borgerhoff Mulder \& Caro (1985) for details of methodology). During these observations, and when it was appropriate, mothers were asked (approximately once a week) about the resources available in the household, the incidence of illness, and the medical treatment sought. Resource availability was measured in terms of the frequency with which important dietary items (milk, meat, eggs or sugar) were present in the household, surplus nutritional items (milk, meat, eggs, vegetables, maize) were sold, cash was available (as evidenced by the purchase of tea or sugar and miscellaneous items from shops at the local Centre), and beer was sold. Purchases were recorded only if they had been made either on the day of my visit, or the previous day. These measures are clearly not independent of one another; for instance, a woman with few milkers may be forced to buy milk, and consequently to sell beer, the primary means of raising cash. Alternatively, a family with meat available will be able to sell milk, and perhaps use the cash to buy a new blanket. Each measure is reported here simply to depict the different types of economic conditions experienced by different households.

For mothers, the incidence of sickness was measured in terms of the proportion of my visits to each mother at which she reported being ill. The mean number of children reported ill per household (averaged across visits) was divided by the number of children resident in the household, producing a measure of the average probability of any one child in a particular household being sick. Analyses were restricted to children under 14 years of age.

The type of treatment afforded ill children was measured in terms of the proportion of cases where one or more sick children had been taken to the dispensary or hospital. The interval between onset of symptoms and administration of treatment was also recorded.

\section{Results}

Wealth and reproductive success in Kipsigis women

Significant positive correlations were found between the number of acres-per-wife and a 
TABLE III

Spearman rank correlation coefficients between acres-per-wife and the frequencies with which nutritional and cash resources were available in each household ${ }^{\mathrm{a}, \mathrm{b}}$

\begin{tabular}{lcc}
\hline & \multicolumn{1}{c}{$r_{s}$} & $P$-value \\
\cline { 1 - 2 } Availability of nutritional subsistence & items \\
Milk & 0.59 & $<0.001$ \\
Meat/eggs & 0.24 & $<0.01$ \\
Sugar & 0.28 & $<0.01$ \\
Surplus nutritional items sold & \\
Milk & 0.27 & $<0.01$ \\
Meat/eggs & 0.09 & $\mathrm{~N} . \mathrm{S}$. \\
Vegetables & 0.10 & $\mathrm{~N} . S$ \\
Maize & 0.30 & $<0.01$ \\
Cash availability, as evidenced by purchases \\
Tea/sugar & 0.18 & $<0.05$ \\
Miscellaneous items & 0.19 & $<0.05$ \\
Cash shortage & & \\
Sale of beer & -0.31 & $<0.001$ \\
\end{tabular}

\footnotetext{
"Spearman rank correlations used because data were not normally distributed.

${ }^{b} 118$ households

${ }^{c}$ Maize was excluded from analysis because it was always available in all households, even if only a few handfuls had been borrowed from a neighbour.

${ }^{d}$ See p. 000.
}

woman's reproductive success in the 'Chuma' cohort, Cohort I and Cohort III (Table I), although no more than $5 \%$ of the variance could be explained by wealth differences in any cohort. The relationship between lifetime reproductive success and acres-per-wife is plotted for 'Chuma' women (Fig. 1).

In the 'Chuma' cohort and Cohort I, acres-per-wife was positively associated with the probability that offspring survive (Table II). The association between acres-per-wife and offspring survival was primarily due to higher probabilities of offspring surviving between 18 months and 5 years $(r=0.29, N=150, P<0.001$ for 'Chuma' and $r=0.16, N=156, P<0.05$ for Cohort I). In the 'Maina' cohort, offspring of wealthy women experienced higher survivorship through infancy $(r=0.38, N=31, P<0.05)$ than did offspring of poor women, although there was no effect of wealth on the overall probability of offspring survival.

As regards fertility, acres-per-wife was positively associated with the number of live-births per year in Cohorts I and III (see also Table II).

In sum, the number of acres to which a women has access was positively and significantly associated with her reproductive success, offspring survival and/or fertility in three of the five cohorts for which data were available. In the two remaining cohorts, the associations were pusitive but not significant. The results were independent of other factors affecting reproduction in these cohorts (husband's age, widowed status, age at menarche, wife's education and marriage year; see 


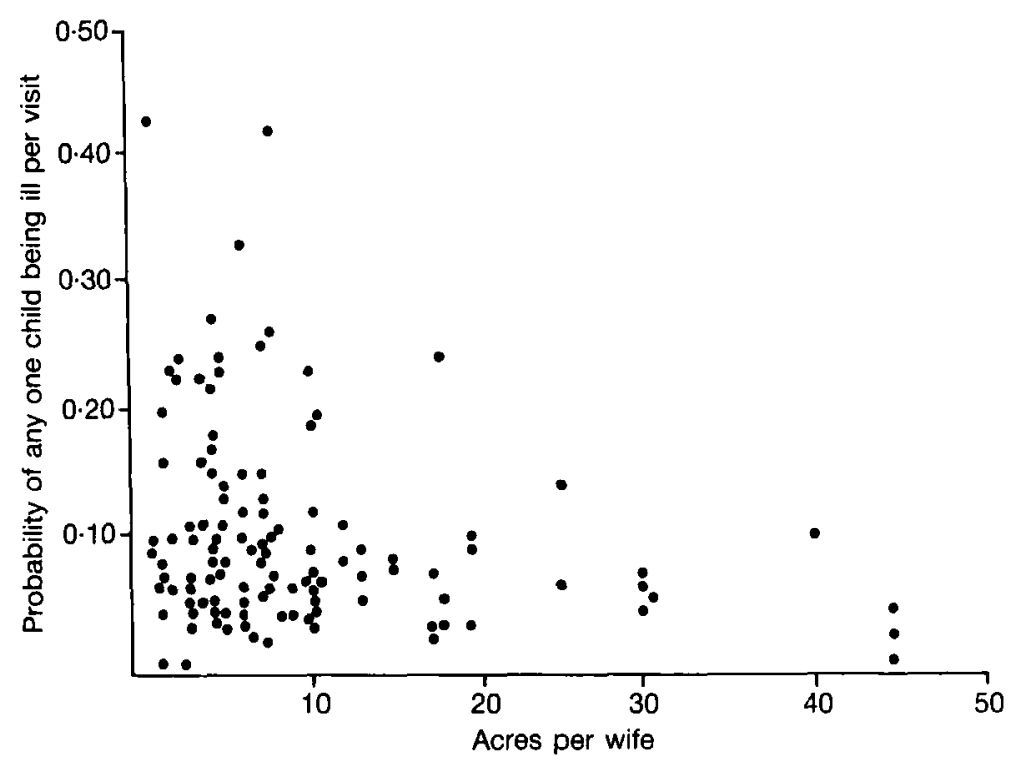

F1G. 2. The probability of any one of a woman's children being sick at the time she was visited, plotted against acres-perwife $\left(r_{s}=0.22, N=114, P<0 \cdot 05\right)$. (Four households were excluded from these analyses because they contained no children under 14 years of age.)

notes to Tables I and II, and Borgerhoff Mulder, 1987a), although the amount of variance explained by wealth alone was small.

\section{Wealth, food availability and health in Kipsigis women}

To what factors can the reproductive advantages of wealthy Kipsigis women be linked?

The first possibility is that a greater proportion of their reproductive years are spent married. In no cohort did wealthy women marry earlier than poor women, nor did they experience significantly longer reproductive lifespans (Borgerhoff Mulder, 1987a); furthermore, with no divorce permitted in Kipsigis society, greater marital stability could be excluded as an explanation for the higher reproductive success of wealthy women.

A second possible reason might be that wealthy women use western medical services more frequently and with less delay than do poor women. Weekly interviews suggested that this was not the case. The proportion of cases per household where one or more sick children had received dispensary or hospital treatment did not differ according to wife's wealth $\left(r_{s}=-0 \cdot 13, r_{s}=-0 \cdot 04\right.$, N.S.; households were dropped from the analysis where less than three instances of illness had been monitored $(N=19)$ or where no child had been sick $(N=3)$, leaving 92 households). Similarly, the proportion of cases where one or more sick children had either been treated within two days of onset of symptoms or had not received any treatment within seven days of onset of symptoms was not associated with wife's wealth $\left(r_{s}=0 \cdot 00,-0.02, N=76\right.$, N.S.; a further 16 households were dropped where the interval to treatment was monitored on less than three occasions in any household).

To examine whether differences in nutrition and health might be implicated in the high 
reproductive success of wealthy women, the frequencies with which resources were present in households were analysed according to acres-per-wife (Table III). Wealthy women more commonly had milk, meat or eggs and sugar in the household than did poor women; furthermore, they had more frequently sold milk or maize on the day of my visit (or the previous day) and had more commonly bought tea or sugar and miscellaneous items. In addition, they were less likely to have brewed and sold beer for cash.

As regards the association between resources and health, wealthy women and their children had lower frequencies of illness than did poor women. The average probability that any one of a mother's children was ill on any of my visits was negatively associated with the size of the mother's plot (Fig. 2). Furthermore, a mother's probability of being ill on any one visit was also negatively associated with the size of her plot $\left(r_{s}=-0.24, N=118, P<0.01\right)$.

In short, wealthy women have nutritional resources and cash more commonly available in the household than do poor women, and they and their children are less frequently ill. Wealthy women do not differ from poor women in the frequency or speed with which they seek western medicine for sick children.

\section{Discussion}

\section{Reproductive measures}

For a clear understanding of how differential access to resources is associated with fitness, detailed reproductive life histories of individuals are required from which longevity, fertility and offspring survival probabilities can be calculated (Clutton-Brock, in press). In many human societies such information is rarely available.

Data on completed family size are often taken from government census returns that may be inaccurate, particularly if under-reporting of household members reduces taxation demands. For historical data, individual reproductive life histories are reconstructed from parish registers of baptisms, weddings and funerals (cf. Wrigley, 1966), and ingenious methods can be used to calculate fecundity and post-partum amenorrhoea from such records (cf. Knodel \& Wilson, 1981); parish registers nevertheless suffer from a number of serious biases due to such factors as local migration between parishes and under-reporting of first births (Wilson, 1986). Even where individuals can be personally interviewed about their reproductive careers, as in contemporary non-literate populations, serious problems of accuracy, recall and bias can arise (Howell, 1979; Borgerhoff Mulder, in press $a$ ); furthermore, for reasons of cultural propriety, it may be impossible to determine rates of offspring mortality. Finally, many demographic studies focus primarily on the measure of fertility (number of births) that may bear little relation to fitness, measured as the number of surviving offspring.

Such shortcomings in the quality of the data in no way render demographic studies in developing, historical or traditional societies invalid. However, few studies present systematic analyses of the correlations between wealth and the components of reproductive success. Without such data it is difficult to examine the precise mechanisms whereby resources affect reproduction, or to account for why this relationship varies in different social and ecological conditions as in nonhuman primates (Abbott, 1987; Harcourt, 1987).

In the Kipsigis study, it was possible to obtain measures of fertility and offspring survival and (for women married before 1954) length of married reproductive lifespan, and to determine the correlation coefficients of each of these components with acres-per-wife. The quality of the data 
was checked in a smaller sub-sample of families (Borgerhoff Mulder, in press $a$ ) whose reliability had been established through detailed behavioural study.

Results showed that wealthy women had higher reproductive success, fertility and offspring survival than poor women. Differences in fertility were not due to differences in exposure to sexual intercourse, at least in so far as only married women were compared. Differences in offspring mortality could not be attributed to any current wealth-related differences in the use of western medicine. Secular changes in the correlation between wealth and the components of fitness were examined by repeating the analyses across cohorts (see below).

\section{Wealth as a cause or consequence of high reproductive success}

Demographers and anthropologists question whether preferential access to resources is a cause or a consequence of reproductive success. In labour-intensive production systems parents may become wealthy as a result of the labour inputs of their numerous progeny. Some studies conclude that this is the case (Nag et al., 1978). Others question (Hull, 1978) or exclude such an explanation (Irons, 1980; Turke \& Betzig, 1985), claiming that differential access to resources is an important determinant of reproductive success in that particular society.

Alternatively, it has been proposed that correlations between farm and family size in peasant societies where land is commonly rented (such as pre-revolutionary Russia and Poland) may result from the greater need of large families for land (Chayanov, 1966); this questions (see Simon, 1974) the validity of the now classic finding of a positive correlation between farm and family size in Polish peasantry (Stys, 1957). Clearly, extensive social and economic background material should be presented on how individuals become wealthy, if correlations are to be interpreted as evidence substantiating differential access to resources as a determinant of reproductive success.

In the Kipsigis case, wealth differences are unlikely to be a consequence of the productive efforts of children, in so far as positive correlations between wealth and reproductive success are found even in the most recent cohorts where children are still too young to be productive (see also Borgerhoff Mulder, in press $a$ ). Furthermore it is unlikely that a man with one or more extraordinarily reproductively successful wives is spurred (perhaps by necessity) into acquiring more land, to feed and settle the offspring of these wives. First, as noted above, the correlation is found even in recent cohorts, in which there has been little opportunity (in terms of time) for men to accumulate land. Secondly, land is becoming a critical resource among rural Kenyans (Borgerhoff Mulder, 1985), and everyone, not just highly reproductively successful individuals, tries to acquire more land, despite the difficulties in so doing. Thirdly, land is not easily accessible and is rarely on the market; most plots in the study area were settled in 1940 or before, and few families have purchased new land subsequently. In a temporal sense, then, the differences in land ownership generally pre-date the reproductive differences among women analysed in this chapter, particularly those of the 'Chuma' and subsequent cohorts.

In sum, it seems unlikely that the correlation between wealth and reproductive success can be attributed to the differential acquisition of land by men as a result of either the labour inputs of their children or the high reproductive performance of their wives. It therefore appears that wealth is indeed a cause of reproductive success.

\section{Confounding variables, and the role of modernization}

Faced with the inconsistency of the relationships between wealth and reproductive success, 
demographers have become acutely aware that the effects of land-holding (or income) may in some contexts be concealed or exaggerated by the effects of another variable. Likely variables that may confound wealth are occupation, education or differential modernization, each of which may directly or indirectly (through altering family size preferences) affect reproductive success.

In Kipsigis women, the correlations between access to resources and reproductive success were shown to be independent of other significant factors affecting reproduction in these cohorts. The possibility that the large family of a wealthy woman was attributable to her education, age at menarche, husband's age or occupation was excluded by statistical means.

The key factor that confounds studies of the relationship between wealth and women's reproductive success is modernization. Grossly speaking, the degree of modernization is related to family size in an inverted U-shape function, both across individuals within a society and between societies. Women have small families in traditional rural communities. Then, in the early stages of modernization, larger families are observed, due principally to the introduction of medicine, availability of commercial infant foods for early weaning, improvements in general living conditions and breakdown in traditional practices sanctioning breast-feeding, post-partum sexual abstinence and polygyny ( Nag, 1980; Romaniuk, 1980). Together these processes tend to enhance offspring survivorship, to reduce primary sterility that results from treatable venereal disease, to lower the risks of mortality during chidbirth, to shorten lactational amenorrhoea and to increase the frequency with which women have sexual relations. Finally, with higher levels of modernization, particularly extensive education, family size preferences are lowered, modern contraceptive techniques become acceptable and completed family size declines (Central Bureau of Statistics, 1980; Nag, 1980).

In the early stages of modernization, wealthy individuals generally have preferential access to western food and medicine, enjoy improved living conditions, in terms of health, diet and sanitation, and are consequently more able to fulfil the common traditional desire (cf. Fortes, 1978) for large numbers of progeny than are poorer parents (Lang, 1946; Yaukey, 1961; Driver, 1963; Hull \& Hull, 1977; Irons, 1979; Turke \& Betzig, 1985). Under these conditions, the association between wealth and reproductive success will be strong. On the other hand, with further rural modernization, the general conditions of life may be alleviated for even the poorest members of the population, as primary health care becomes generally available on a local basis and seasonal food shortages can be buffered by purchasing subsistence items. Under these conditions, the effects of differential resource access on reproductive success may be dampened and even disappear.

To what extent is the high reproductive success of Kipsigis women a consequence of differential modernization? As regards western medicine, weekly interviews and observations suggest that wealthy women did not make greater use of medical services (hospitals and dispensaries) when their children were sick than did poor women. This is probably because free primary health care, if only at a rudimentary level, has been available at the local level since the mid 1960s. All women have had relatively equal access to these services and appear to make equal use of them. While the situation may have been different in the past (see below), the association between wealth and women's reproductive success appears not to be mediated currently by different use of western medicine.

The more general aspects of modernization (improved sanitary conditions, western preferences for smaller families, etc.) have hardly affected women in the Abosi area (Borgerhoff Mulder, in press $b$ ) and are therefore unlikely to account for the high reproductive success of wealthy women. 
Furthermore, the effects of wealth are independent of education, which is often used as an indication of the degree to which individuals are likely to experience new cultural ideas.

\section{Nutrition, fertility and offspring survival}

High reproductive success among individuals of high status may result from improved nutritional status of women and their children, affecting susceptibility to disease, fertility and mortality (as suggested by many, e.g. Stys, 1957; Irons, 1979; Turke \& Betzig, 1985). Such claims become more convincing when household consumption rates (e.g. Hull \& Hull, 1977), nutritional status (e.g. Howell, 1979) and the incidence of sickness are measured.

The Kipsigis data indicate that wealthy women more commonly had nutritional resources and cash available in the household than did poor women, and that they and their children were less frequently ill, suggesting that there may be advantages in nutrition and health to women and children living on large plots. To what extent can such factors be responsible for reproductive differences in the Kipsigis?

As regards mortality of offspring, it has long been recognized that malnutrition is a major cause of sickness and morbidity in children (Grounds, 1964), and numerous studies now show that children are more at risk of infection if malnourished (e.g. Morley, 1973; Eveleth \& Tanner, 1976; Wood \& Smouse, 1982).

Survival of offspring can also be influenced by maternal nutritional status, through its effects on birth weight. Maternal ill health and inadequate dietary intake prior to and during pregnancy affect birth weight (Ashworth \& Feachem, 1985), and improved nutrition can increase birth weight by up to $10 \%$ (Lechtig \& Kline, 1981). Such increments lead to significant improvements in survival rates of children in developing countries (Prentice, 1980; Ashworth \& Feachem, 1985). The differential chances of survival of children born to rich and poor Kipsigis mothers may therefore be partly due to differences in maternal condition, mediated by differences in birth weight, as also found in red deer (Clutton-Brock et al., 1982).

A further mechanism whereby resource differences between Kipsigis households might affect the survivorship of offspring is through the availability of suitable foodstuffs for weanlings and young children (cf. Wray, 1977; Hill \& Randall, 1984). Supplementary foods, most notably cows' milk and porridge, are ideally introduced to Kipsigis infants at 3-4 months, although breastfeeding will continue for another 20 to 30 months; thereafter the mother usually becomes pregnant again. Women on small plots with few cows frequently deplored the lack of milk to give their small children; indeed Peristiany (1939) indicates that such deprivation may have been a principal cause of offspring mortality in the 1930s. The high rates of illness and mortality of children born to poorer mothers found in the present study may therefore in part result from the relative lack of suitable foodstuffs for infants and young children, leading to nutrition-related complications at weaning.

As regards fertility, the advantages of wealthy women may be related to nutritional factors that affect length of lactational amenorrhoea and, more speculatively, ovarian function.

Duration of lactational amenorrhoea is affected both by the frequency of breast-feeding (Konner \& Worthman, 1980; Wood, Lai, Johnson, Campbell \& Maslar, 1985) and maternal diet (Lunn, Prentice, Whitehead \& Austin, 1980; Lunn, Austin \& Prentice, 1984). The data presented above on the availability of resources in Kipsigis households indicate that the high fertility of wealthy women could be mediated by either of these factors. First, with cows' milk more 
frequently available throughout the year, wealthy women are probably able to introduce traditional supplementary foods earlier, breast-feed less frequently and thereby shorten the period during which elevated plasma-prolactin levels inhibit ovulation. Secondly, even despite continued breast-feeding, wealthy women may experience shortened lactational amenorrhoea as a result of being better nourished, as observed among lactating Gambian women (Lunn, Austin et al., 1984).

There is now some evidence that ovarian function is also related to nutritional status. In cases of severe malnutrition women may cease to cycle (Frisch \& McArthur, 1974; Bongaarts, 1980), even though the mechanisms for such a response may be uncertain and the existence of a 'critical fat' threshold remains unsupported (Scott \& Johnston, 1985). While no Kipsigis women interviewed showed signs of severe malnutrition, cases were encountered in a local hospital (K. Schuit, pers. comm.). It is therefore reasonable to suggest that fertility among poorer women may decline in periods of occasional acute food shortages that occur on both seasonal and annual bases.

Far more speculatively, there are some preliminary suggestions that the length of the ovarian cycle (Johnson, Wood, Campbell \& Maslar, in press) and the proportion of cycles that are anovulatory (Ellison, Peacock \& Lager, 1986) are highly variable between populations of very different nutritional levels. While only tentative conclusions can be drawn at this stage, these findings suggest that intra-populational differences in fertility may also be mediated by the effects of nutrition on fecundity (see Wilmsen, 1986, for a recent review of the evidence).

In the absence of measures of nutritional status of Kipsigis women and children, these lines of argument are at best speculative. They do nevertheless indicate how the availability of resources and incidence of sickness in Kipsigis households may affect both fertility and offspring survival, thereby accounting at least in part for the correlation between acres-per-wife and reproductive success.

\section{Changes in the effects of resources on reproduction}

There is evidence of a change in the nature of the wealth/reproductive success relationship in Kipsigis. In the early period sampled here (pre-1960s), wealth was primarily associated with survivorship of offspring; in the later period (post-1960), wealth was more strongly associated with fertility differences among women. Why should this be?

Nowadays women of different wealth make equal use of medical care, but by all reports this was not so in the past. Only rich women could afford to tra vel to hospital when their children were sick; furthermore a hospital bill of 200 Kenyan shillings or more required the sale of livestock, which might threaten a poor family's subsistence. Under such conditions in the past, when offspring mortality was high (30\%: Borgerhoff Mulder, in press $c$ ), infant and childhood survival rates were higher among wealthy than poor parents ('Maina' and 'Chuma' cohorts and Cohort I). As medicine became generally available and the conditions of life improved (most markedly in the 1960 s in southern Kericho District), the overall levels of offspring mortality declined to approximately $10 \%$ (in the two recent cohorts) and the wealthy no longer show higher rates of offspring survivorship. Under these new socioeconomic conditions, differential access to land is correlated with fertility (Cohorts I and III). Land ownership no longer affects women's ability to raise offspring but their ability to produce them.

Evidence of such a trend is still weak in the Kipsigis; furthermore, it has not been systematically examined in other longitudinal data sets. Such observations nevertheless raise suggestions as to why the association between resources and reproduction is so variable across societies (see Conclusions). 


\section{Conclusions}

A number of conclusions can be drawn from this examination of the nature of the relationship between wealth and reproductive success. These are remarkably similar to conclusions drawn from recent discussions of rank and reproduction in non-human primates.

First, just as there are problems in the measure of rank in non-human primates (Whitten, 1983), so there are difficulties in defining and measuring wealth in humans (Good et al., 1980). Methodological inconsistencies may therefore account for the discrepant findings concerning the effects of wealth on fitness.

In the largely homogenous agro-pastoralist production system of the Kipsigis, the cultivation of maize and the husbandry of livestock are the sole means whereby women can produce food and cash for their families. Both these pursuits depend on the availability of land. Plot size therefore provides a robust measure of differences in food availability and purchasing power among women in this ethnographic context. If food and cash are critical to the production and raising of offspring (see below), plot size will consistently confer reproductive success on women, as is confirmed in many primarily agricultural societies (see Introduction). In more heterogenous societies, where women can support families in a number of alternative ways, simple correlations between land access, salary, occupation or socioeconomic status are less likely to be observed, as is indeed the case (Good et al., 1980). This is because failure in one economic sphere may be offset by success in another. In sum, failure to find consistent correlations between reproductive success and a socioeconomic variable (such as earned income) may simply reflect the fact that earned income is of different economic (and reproductive) importance both across societies and among individuals within a society.

Secondly, whether resources influence reproductive success or not, and which components of fitness are affected, will depend on specific environmental factors (Gouzoules, Gouzoules \& Fedigan, 1982; Harcourt, 1987).

In contemporary humans, one critical feature of the environment is the availability of medicine and other western commodities that initially enhance and subsequently lower reproductive success. In the Kipsigis, the disappearance of the correlation between wealth and offspring survivorship in the two most recent cohorts was attributed to the introduction of widely available primary health care in rural Kenya. However, under a political system where the wealthy enjoy preferential access to medical services for their children, correlations between wealth and offspring survivorship are to be expected. Without data on the mechanisms whereby resources affect reproductive success, in particular wealth-related differences in the use of hospitals and dispensaries, it will be difficult to interpret why wealth is positively correlated with reproductive success in some contexts and not in others.

Thirdly, on the assumption that there exists a threshold above which resource accumulation has negligible effects on reproduction, correlations between wealth and reproductive success are likely to disappear when the least successful competitors reach this threshold. In the Kipsigis such a threshold has not yet been reached, in so far as wealthy women still have higher fertility than do poorer women. More generally, without longitudinal data on wealth-related differences in reproductive success that can be related to environmental changes, it is difficult to determine to what extent the breakdown in the wealth/reproductive success correlation in different societies is due to the superabundance of critical resources.

In conclusion, variability in the relationship between resource access and reproductive success may spring from an inadequate specification of both the nature and the availability of resources 
critical to reproduction. Evolutionary biological theory is not necessarily irrelevant to the study of societies where positive associations between resources and reproduction are not found (as suggested by Vining, 1986), particularly before these methodological and conceptual problems are addressed (see also Borgerhoff Mulder, 1987b). Furthermore, phenotypic traits other than competitive ability over access to resources should be examined. The selective advantage of a modern woman's reproductive strategy may be better understood by looking at the effects of, for example, economic independence, choosiness in mating, social attractiveness and use of contraception on her fitness and that of her offspring.

\section{Summary}

The effects of differential access to resources on the reproductive success of women are examined in the polygynous, agro-pastoralist Kipsigis people of south-western Kenya.

The critical subsistence resource (land) is owned by men. Women attain access to land through marriage. Women with access to large plots (wealthy women) have higher lifetime reproductive success than do their poorer counterparts in three out of the five marriage cohorts studied. This is due to both enhanced fertility and survivorship of offspring.

The high reproductive success of wealthy women is likely to be a consequence rather than a cause of differences in wealth, and is not currently due to differential use of western medical services. Weekly interviews indicate that wealthy women more frequently have nutritional resources and cash available in the household, and that they and their offspring are less commonly ill. These findings suggest that wealth-related differences in the nutrition and health of mothers and children may in part account for reproductive differentials among Kipsigis women.

It is proposed that the inconsistency in the relationship between access to resources and reproductive performance of women across societies springs from both an inadequate specification of the resources critical to reproduction and a failure to understand the mechanisms whereby resources confer reproductive benefits on women.

I thank the Office of the President in Nairobi, for permission to conduct research in Kenya, all the Kipsigis people of Abosi for their constant cooperation and friendship during the fieldwork, and the family of Philip Arap Bii for their hospitality. Tim Clutton-Brock, Steve Albon and all the members of the Large Animal Research Group, Department of Zoology, Cambridge, offered invaluable advice and discussion during the analysis of these data. Tim Caro's suggestions and critical reading of earlier drafts helped enormously in sorting out ideas and Phyllis Lee offered useful comments. The research was funded by the National Geographic Society, and analysis by the Northwestern University Department of Anthropology. Some of the conclusions drawn from this study have recently been suggested by Handwerker (1986) in discussing contradictory results from studies of demographic transition.

\section{REFERENCES}

Abbott, D. H. (1987). Behaviourally mediated suppression of reproduction in female primates. J. Zool., Lond. Ajami, I. (1976). Differential fertility in peasant communities: a study of six Iranian villages. Popul. Stud. 30: 453-463. Ashworth, A. \& Feachem, R. G. (1985). Interventions for the control of diarrhoeal diseases among young children: prevention of low birth weight. Bull. Wld Hlth Org. 63: 165184.

Bongaarts, J. (1980). Does malnutrition affect fecundity? A summary of the evidence. Science, N.Y. 208: 565-569.

Borgerhoff Mulder, M. (1985). Polygyny threshold: a Kipsigis case study. Natn. geogr. Case Rep. 21 : 33-39.

Borgerhoff Mulder, M. (1987a). Marriage and reproduction in the Kipsigis of Kenya. PhD dissertation: Northwestern University Department of Anthropology. 
Borgerhoff Mulder, M. (1987b). Adaptation and evolutionary approaches to anthropology. Man 22: 35-41

Borgerhoff Mulder, M. (In press $a$ ). On cultural and reproductive success: Kipsigis evidence. Am. Anthrop.

Borgerhoff Mulder, M. (In press $b$ ). Low reproductive performance and women's age at the onset of reproduction. Anthrop. Közl.

Borgerhoff Mulder, M. (In press $c$ ). Reproductive success in three Kipsigis cohorts. In Reproductive success: studies of selection and adaptation in contrasting breeding systems. Clutton-Brock, T. H. (Ed.). Chicago: Chicago University Press.

Borgerhoff Mulder, M. \& Caro, T. M. (1985). The use of quantitative observational techniques in anthropology. Curr. Anthrop. 26: 323-335.

Borgerhoff Mulder, M. \& Milton, M. (1985). Factors affecting infant care in the Kipsigis. J. anthrop. Res. 41: 231-262.

Central Bureau of Statistics (1980). Kenya fertility survey, 1977-78. Nairobi: Ministry of Economic Planning and Development.

Chayanov, A. V. (1966). The theory of peasant economy. Thorner, D., Kerblay, B. \& Smith, R. E. F. (Eds). Homewood: Irwin.

Clutton-Brock, T. H. (In press). Reproductive success. In Reproductive success: studies of selection and adaptation in contrasting breeding systems. Clutton-Brock, T. H. (Ed.). Chicago: Chicago University Press.

Clutton-Brock, T. H., Guinness, F. E. \& Albon, S. A. (1982). Red deer. Behavior and ecology of two sexes. Chicago: Chicago University Press; Edinburgh: Edinburgh University Press.

Driver, E. D. (1963). Differential fertility in central India. Princeton: Princeton University Press.

Ellison, P. T.. Peacock, N. R. \& Lager, C. (1986). Salivary progesterone and luteal function in two low-fertility populations of north east Zaire. Hum. Biol. 58: 473-483.

Essock-Vitale, S. M. (1984). The reproductive success of wealthy Americans. Ethol. Sociobiol. 5: 45-49.

Eveleth, P. B. \& Tanner, J. M. (1976). Worldwide variation in human grow'th. Cambridge: Cambridge University Press.

Flinn, M. V. (1986). Correlates of reproductive success in a Caribbean village. Hum. Ecol. 14: 225 243.

Fortes, M. (1978). Parenthood, marriage and fertility in West Africa. In Population and development: high and low fertility in poorer countries: 121-149. Hawthorn, G. (Ed.). London: Cass.

Frisch, R. E. \& McArthur, J. W. (1974). Menstrual cycles: fatness as a determinant of minimum weight for height necessary for the maintenance and onset. Science, N.Y. 185: 949-951.

Good, M. D., Farr, G. M. \& Good, B. (1980). Social status and fertility: a study of a town and three villages in Northwestern Iran. Popul. Siud. 34: 311-335.

Gouzoules, H., Gouzoules, S. \& Fedigan, L. (1982). Behavioural dominance and reproductive success in female Japanese monkeys (Macaca fuscata). Anim. Behav. 30: 1138-1150.

Grounds, J. G. (1964). Mortality of children under six years old in Kenya with special reference to contributory causes. especially malnutrition. J. trop. Med. Hyg. 67: 257-259.

Handwerker, W. P. (1986). Culture and reproduction: explaining micro/macro linkages. In Culture and reproduction; an anthropological critique of demographic transition theory: 1-28. Handwerker, W. P. (Ed.). Boulder: West View.

Harcourt, A. H. (1987). Dominance and fertility among female primates. J. Zool., Lond.

Hawthorn, G. (1970). The sociology of fertility. London: Macmillan.

Hill, A. G. \& Randall, S. C. (1984). Différences géographiques et sociales entre la mortalité infantile et juvenile au Mali. Population, Paris: 40: 921-946.

Howell, N. (1979). The demography of the Dobe!Kung. New York: Academic Press.

Hull, T. H. (1978). [Comment on Nag et al. (1978)]. Curr. Anthrop. 19: 301-302.

Hull, T. H. \& Hull, V. V. J. (1977). The relationship of economic class and fertility: an analysis of some Indonesian data. Popul. Stud. 31: 43-57.

Irons, W. G. (1979). Cultural and biological success. In Evolutionary biology and human social behavior: an anthropological perspective: 257-272. Chagnon, N. A. \& Irons, W. G. (Eds). North Scituate, Mass.: Duxbury Press.

Irons, W. G. (1980). Is Yomut social behavior adaptive? In Sociobiology: beyond nature/nurture?: 476 . 489. Barlow, G. \& Silverberg, J. (Eds). Boulder: West View.

Johnson, P. L., Wood, J. W., Campbell, K. L. \& Maslar, I. A. (In press). Long ovarian cycles in women of Highland New Guinea. Hum. Biol.

Konner, M. \& Worthman, C. (1980). Nursing frequency, gonadal function and birth spacing among !Kung huntergatherers. Science, N.Y. 207: 788-791.

Knodel, J. \& Wilson, C. (1981). The secular increase in fecundity in German village populations: an analysis of reproductive histories of couples married 1750-1899. Popul. Stud. 35: 53-84.

Lang, O. (1946). Chinese family and society. Yale: Yale University Press. 
Lechtig, A. \& Kline, R. E. (1981). Prenatal nutrition and birth weight: is there a causal association? In Maternal nutrition in pregnancy-eating for two: 131-156. Dobbing, J. (Ed.). London: Academic Press.

Lunn, P. G., Austin, S. \& Prentice, A. M. (1984). The effects of improved nutrition on plasma prolactin concentrations and postpartum infertility in lactating Gambian women. Am. J. clin. Nutr. 39: 227-235.

Lunn, P. G., Prentice, A. M., Whitehead, R. G. \& Austin, S. (1980). Influence of maternal diet on plasma-prolactin levels during lactation. Lancet 1980 (i): 623625 .

Manners, R. A. (1967). The Kipsigis of Kenya: culture change in a 'model' East African tribe. In Contemporary change in traditional societies 1: Introduction and African tribes: 207-359. Steward, J. (Ed.). Urbana: University of Illinois Press.

Merrick, T. W. (1978). Fertility and land availability in rural Brazil. Demography 15: 321-336.

Morley, D. (1973). Pediatric priorities in the developing world. London: Butterworth.

Nag. M. (1980). How modernization can also increase fertility. Curr. Anthrop. 21: 571-588.

Nag, M., White, B. N. F. \& Peet, R. C. (1978). An anthropological approach to the study of the economic value of children in Java and Nepal. Curr. Anthrop. 19: 293-306.

Orchardson, 1. Q. (1961). The Kipsigis. Nairobi: Kenya Literature Bureau.

Peristiany, J. G. (1939). The social institutions of the Kipsigis. London: Routledge \& Kegan Paul.

Prentice, A. M. (1980). Variations in maternal dietary intake, birthweights and breast-milk output in the Gambia. In Maternal nutrition during pregnancy and lactation: 167-183. Aebi, H. \& Whitehead, R. G. (Eds). Bonn: Hans Huber.

Reed, S. C. \& Palm, J. D. (1951). Social fitness versus reproductive fitness. Science, N. Y. 113: 294-296.

Romaniuk, A. (1980). Increase in natural fertility during the early stages of modernization: evidence from an African case study, Zaire. Popul. Stud. 34: $293-310$.

Scott, E. C. \& Johnston, F. E. (1985). Science, nutrition, fat and policy: tests of the critical-fat hypothesis. Curr. Anthrop. 26: 463-473.

Shaikh, K. \& Becker, S. (1985). Socioeconomic status and fertility in rural Bangladesh. J. biosoc. Sci. 17: 81-89.

Shorter, E. (1975). The makings of the modern family. London: Basic Books.

Simon, J. L. (1974). The effects of income on fertility. Chapel Hill: University of North Carolina Press.

Stys, N. (1957). The influence of economic conditions on fertility of peasant women. Popul. Stud. 11: $136-148$.

Turke, P. W. \& Betzig, L. L. (1985). Those who can do: wealth, status and reproductive success on Ifaluk. Ethol. Sociobiol. 6: $79-86$.

Vehrencamp, S. L. \& Bradbury, J. W. (1984). Mating systems and ecology. In Behaviouralecology': 251-278. Krebs, J. R. \& Davies, N. B. (Eds). Oxford: Blackwells.

Vining, D. R. Jr. (1986). Social versus reproductive success: the central theoretical problem of human sociobiology. Behar. Brain Sci. 9: 167-216.

Whitten, P. L. (1983). Diet and dominance among female vervet monkeys (Cercopithecus aethiops). Am. J. Primatol. 5: 139-159.

Wilmsen, E. N. (1986). Biological determinants of fecundity and fecundability: an application of Bongaarts' model to forager fertility. In Culture and reproduction: an anthropological critique of demographic transition theory: $59-89$. Handwerker, W. P. (Ed.). Boulder: West View.

Wilson, C. (1986). The proximate determinants of marital fertility in England 1600-1799. In The world we hate gained: histories of population and social structure: 203-230. Bonfield, L., Wrightson. K. \& Smith, R. M. (Eds). Oxford: Blackwell.

Wood, J. W., Lai, D., Johnson, P. L.. Campbell, K. L. \& Maslar, I. A. (1985). Lactation and birth spacing in Highland New Guinea. J. biosoc. Sci. Suppl. 9: 159 - 173.

Wood, J. W. \& Smouse, P. E. (1982) A method of analyzing density-dependent vital rates with an application to the Gainj of Papua New Guinea. Am. J. phys. Anthrop. 58: $403-411$.

Wrangham, R. W. (1979). On the evolution of ape social systems. Soc. Sci. Inf. 18: 335-368.

Wray. M. D. (1977). Maternal nutrition, breast feeding and infant survival. In Nutrition and human reproduction: 197-230. Mosley, W. H. (Ed.). New York: Plenum Press.

Wrigley. E. A. (1966). Population and history. New York: McGraw-Hill.

Wrong, D. (1961). Population and society. New York: Random Press

Yaukey, D. (1961). Fertility differences in a modernizing country: a surtey of Lehanese couples. Princeton: Princeton University Press. 
